\title{
Um milhão de Revendedoras de Cosméticos: Aspectos de um Trabalho Amórfico e o Novo Panorama do Mundo do Trabalho
}

ABÍLIO, Ludmila Costhek. Sem maquiagem: o trabalho de um milhão de revendedoras de cosméticos. São Paulo: Boitempo, 2014, 240p. (Coleção Mundo do Trabalho).

POR

\section{Silvio Matheus Alves Santos ${ }^{1}$}

O livro "Sem maquiagem: o trabalho de um milhão de revendedoras de cosméticos", escrito pela socióloga Ludmila Abílio, é resultado de uma tese de doutorado em ciências sociais, apresentada em 2012, na Unicamp. Nele, a autora apresenta a pesquisa que realizou sobre as relações de trabalho existentes em uma das maiores empresas nacionais do mercado de cosméticos, a Natura, trazendo contribuições que ultrapassam o seu universo empírico de pesquisa, fato que, não nos deixa dúvidas de que estamos diante de um trabalho singular e de grande importância, podendo até ser desde já concebido como uma referência não só pelo fato de nos apresentar a realidade de trabalho de um milhão de revendedoras da Natura, mas, sobretudo, por desvelar as novas configurações que compõem o mundo do trabalho.

Sendo um pesquisador das relações de trabalho e dos processos decorrentes da organização flexível de uma fast fashion (multinacional) do comércio varejista de moda ${ }^{2}$, afirmo satisfatoriamente que o que encontramos

1 Doutorando do Programa de Pós-Graduação em Sociologia da Universidade de São Paulo (USP), Brasil. silviomatheus@usp.br

2 Essa pesquisa de mestrado (SANTOS, 2013) tratou sobre o trabalho numa multinacional 
no livro de Ludmila Abílio está para além dos resultados de uma pesquisa relacionada unicamente a uma empresa do mundo da beleza. Evidenciamos que são problematizações que avançam o debate sobre o trabalho informal, a questão do tempo de trabalho e de não trabalho, além dos desdobramentos e das implicações de uma acumulação cada vez mais latente e espraiada. Enfim, as suas reflexões e proposições atualizam um importante debate no que tange às transformações do mundo do trabalho (pensando a realidade brasileira e internacional) e que diz respeito às centralidades: do trabalho, da marca, do imaterial, da acumulação e da banalização da exploração do trabalho.

As questões apresentadas por Ludmila Abílio perpassam as dinâmicas do setor da indústria de cosméticos, do setor informal e do setor de serviços. A autora tem como foco inicial "problematizar a informalidade e a exploração do trabalho em suas formas contemporâneas" (ABÍLIO, 2014, p. 14), tomando como "ponto de apoio as relações e a forma de trabalho informal das consultoras ou revendedoras" da Natura. Para tanto, mergulhou no mundo do "Sistema de Vendas Diretas - SVD, nome técnico que define a forma de relação funcional que liga as revendedoras à empresa", que assume, na visão da autora, uma "expressão bem-acabada da flexibilização do trabalho" (ABÍLIO, 2014, p. 84).

Partindo dessa discussão inicial, intencionamos aqui explicitar, de modo geral, alguns pontos que julgamos centrais e relevantes, partindo das divisões dos capítulos realizadas pela própria autora. É fato que a leitura do livro torna-se necessária, posto que os temas abordados e discutidos são bem instigantes e nos possibilitam compreender de forma mais aprofundada as

fast fashion do comércio varejista, tendo como centro de análise os trabalhadores estáveis que estão inseridos numa organização do trabalho flexível, numa lógica de competências e multifuncionalidade, na busca de metas presentes no plano de carreira. Nesse contexto, constatamos processos de intensificação e precarização do trabalho ao investigarmos como os trabalhadores absorvem as responsabilidades das metas (profissionais e pessoais) colocadas pela empresa e seus impactos. A pesquisa foi realizada em duas lojas da rede de fast fashion C\&A Modas de Aracaju - Sergipe, no ano de 2011. 
novas configurações das relações e organizações do trabalho, seja no setor formal seja na informalidade, tanto no contexto nacional quanto global.

$\mathrm{Na}$ introdução do livro, a autora nos chama a atenção para a "heterogeneidade do perfil socioeconômico" das revendedoras, ponto do qual ela partiu para dar início às definições do trabalho realizado por elas como seu objeto de pesquisa, o que se justifica, em parte, pela afirmação da autora de que "vender Natura pode ser um dos 'bicos' que compõem a renda de trabalhadores qualificados e não tão qualificados" (ABÍLIO, 2014, p. 14). Assim, ressaltamos que no seu trabalho de campo, Abílio se deparou com "consultoras que eram empregadas domésticas, estudantes universitárias, donas de casa da classe alta paulistana, entre outras ocupações e situações econômicas" (ABÍLIO, 2014, p. 14). No que concerne ao SVD, ele será problematizado em muitas passagens do livro e se apresenta como um dos focos centrais na abordagem sobre o trabalho das revendedoras, possuindo uma "estreita relação com o desemprego e a flexibilização do trabalho", além disso, "sua alta permeabilidade e ausência de formas publicamente definidas" o possibilita adequar-se "muito bem à polivalência precária que hoje permeia a sobrevivência no mercado de trabalho"3 (ABÍLIO, 2014, p. 14).

$\mathrm{O}$ conceito de viração ${ }^{4}$, apresentado por Vera Telles, também transitará por todo o trabalho. Esse conceito ganha força ao ser relacionado

3 Os grifos aqui destacados e ao longo do texto foram feitos pelo autor da resenha.

4 Apesar do termo "viração" ter sido utilizado e amplamente discutido na obra de Vera Telles - A cidade nas fronteiras do legal e ilegal -, preferimos utilizar uma compreensão que está numa passagem do livro Saídas de Emergência - especificamente, na parte com o título de "Perspectivas", cunhado pelos autores Robert Cabanes e Isabel Georges (2011, p. 14). onde esse termo é compreendido da seguinte forma: “A diversificação e a complexificação da matriz social do trabalho estão ligadas, portanto, ao aparecimento de novas formas de trabalho e ao seu caráter efêmero que se interpenetram nas trajetórias de vida. Isso concerne às camadas da população que vivem do trabalho e, sobretudo, às camadas mais baixas da escala social. Além de ser uma questão de sobrevivência, que sempre se colocou para a grande maioria, é também uma questão fundamental de existência e reconhecimento sociais. Pego entre a estratégia improvável de acesso a um emprego estável e de qualidade e a estratégia inevitável da viração, o trabalhador é obrigado a recorrer a todos os meios disponíveis". 
com a realidade de vida e de trabalho das revendedoras da Natura. Assim, parte-se "da dimensão do trabalho informal e do reconhecimento dos elos entre 'viração' e a acumulação", enxergando-os "como definidores do ponto de partida da sua pesquisa". Ao longo do livro, "a relação entre o moderno e precário se atualiza" (ABÍLIO, 2014, p.15), bem como novas definições são estabelecidas. A partir disso, Abílio demarca a sua perspectiva sociológica: ela afirma que "tratar do trabalho é também tratar da acumulação e, portanto, de formas contemporâneas da exploração." (ABÍLIO, 2014, p.18).

No primeiro capítulo, As revendedoras e a empresa, a autora buscou nos dar "um panorama dos perfis socioeconômicos das revendedoras e da relação que elas mantêm com as vendas, assim como descrever a maleabilidade dessa ocupação e algumas características da empresa." (ABÍLIO, 2014, p. 19) A autora ainda apresenta os caminhos percorridos na pesquisa empírica (tanto em território nacional quanto internacional), os momentos das entrevistas e seus resultados através de relatos reveladores sobre a realidade de trabalho destas consultoras. A socióloga, a partir de entrevistas, construiu e apresentou alguns "tipos sociais" com base nas especificidades do trabalho, nas suas condições materiais de realização, nas relações que estabelecem com a Natura, etc. e que dentro destas especificidades de trabalho das consultoras, há ainda a existência da revendedora da revendedora o que acaba desencadeando uma informalidade dentro da informalidade.

Outra questão extremamente importante diz respeito ao trabalho formal visto como um diferencial para a manutenção das vendas. Ou seja, “ter um local de trabalho definido assegura também a rotina da atividade. A alta permeabilidade das vendas possibilitou que seu local de trabalho se tornasse sua loja difusa. A falta de formas predefinidas das vendas garante a alta adaptabilidade de uma ocupação à outra." (ABÍLIO, 2014, p.30). Com isso, esse processo de trabalho, pensado e compreendido por nós, como amórfico (termo que deriva de amorfia e que expressa a ausência de forma determinada), "se imbrica nas relações pessoais em espaços privados, a venda não concorre e sim se entrelaça a outras ocupações" (ABÍLIO, 2014, p. 31). Dessa forma, 
"secretárias, recepcionistas, professoras, investigadoras de polícia, entre outras profissionais, são vendedoras (ou consultoras) durante suas jornadas de trabalho." (ABÍLIO, 2014, p. 31).

No capítulo dois, A informalidade e a questão social, a socióloga problematiza o sucesso do SVD como um trabalho predominantemente feminino e destaca a ausência de mediações públicas dessa relação de trabalho. Nessa falta de mediações bem definidas, o que se destaca é a presença da marca sendo “o que aparentemente faz o elo na atividade de todas as consultoras, uma vez que as mais diferentes formas e estratégias de venda têm em comum o discurso da marca. Ela constitui, assim, uma unidade fenomênica a essa multidão de vendedoras." (ABÍLIO, 2014, p. 131). A autora reforça a importância de entender

[...] o papel ativo do Estado nas regulações que hoje são denominadas desregulamentações. Trata-se de triangulações especificas entre Estado, capital e trabalho que se atualizam, e que nas últimas décadas propiciaram diversas formas de precarização e novas configurações do trabalho informal (ABÍLIO, 2014, p. 46).

Abílio, ao ampliar sua escala de análise, centrando-se na teoria marxiana do valor, procura responder algumas questões centrais: como tratar o regime de revendas, de maneira teórica, em termos de exploração do trabalho? Ou ainda, como analisar o fator exploração a partir das implicações entre tempo de trabalho e de não trabalho, trabalho e consumo, nas atividades em que essas dimensões estão imbricadas?

Dessa forma, o capítulo três, A ficção real da acumulação, será orientado pela discussão sobre a desfetichização da marca, que abrirá caminho para o debate sobre a relação entre a dominância da valorização financeira e a precarização do trabalho. A partir das abordagens de Naomi Klein, Isleide Fontenelle e George Ritzer, a autora compreende que a marca pode, então, ser tomada como aquilo que dá "formas fictícias aos elos entre o capital, trabalho e consumo no contemporâneo" (ABÍLIO, 2014, p. 99). No caso das revendedoras, a análise feita sobre a marca nos leva ao consumo e "a partir 
daí podemos reconhecer a imbricação do consumo no trabalho", já que ele se constitui como a entrada principal das revendedoras, segundo o estudo, à informalidade das vendas de produtos da Natura. Portanto, a perspectiva da análise "é a de que a visibilidade contemporânea da marca se combina com a invisibilidade social que hoje permeia as relações de exploração." (ABÍLIO, 2014, p. 99).

O capítulo quatro, A organização na dispersão, traz questões que estão diretamente ligadas ao controle do trabalho. Abílio apresenta como a relação de trabalho das revendedoras da Natura está organizada pela dispersão, "pela ausência de formas de trabalho, pela ausência de locais de trabalho" (ABÍLIO, 2014, p. 132), sem, contudo, deixar de estar controlada. De acordo com a autora, "a forma indefinida, flexível e adaptável que parece costurada pela marca" (ABÍLIO, 2014, p. 132), também é amarrada pela rigidez de boletos de pagamento, cotas de vendas, juros, invalidação de CPF na Serasa, "entre outros modos de controle menos reconhecíveis." (ABÍLIO, 2014, p. 132). Assim, para a autora, "a dispersão pode ser compreendida como parte da constituição contemporânea do controle do trabalho." (ABÍLIO, 2014, p. 132). É nesse sentido que Abílio levanta a hipótese, de que novas formas de controle do trabalho estejam em jogo e, ao pensar na multidão de um milhão de revendedoras, ela chega à conclusão de que "o controle se realizaria na própria dispersão e na própria indiscernibilidade da relação de trabalho" (ABÍLIO, 2014, p. 132). A autora ainda nos apresenta uma discussão sobre a descartabilidade social em relação à banalização da exploração do trabalho. O propósito dela é abrir caminhos para pensar essa descartabilidade "como elemento importante da constituição de uma produtividade sem formas bem definidas e em expansão." (ABÍLIO, 2014, p. 172).

No quinto e último capítulo, Subsunção contemporânea do trabalho e acumulação, Ludmila Abílio se aproxima do toyotismo, entendendo-o como uma expressão da reestruturação e relacionando-o com as formas de subsunção do trabalho. De acordo com a autora "há algo novo na exploração: o envolvimento do trabalhador com o trabalho parece ter cada 
vez menos limites." (ABÍLIO, 2014, p. 172). Esse envolvimento se constitui o cerne deste capítulo, ao relacionar-se com a produtividade do trabalho na sua composição contemporânea. A partir disso, a autora nos aproxima dos problemas encontrados na realidade de trabalho das revendedoras e demonstra uma relação direta com o que foi problematizado:

[...] o envolvimento com o trabalho para além do trabalho evidencia a privatização do tempo de não trabalho. Esse envolvimento agora pode ser entendido pelos elos entre zelo e medo: trata-se da plena atividade que dá sentidos subjetivos ao trabalho ao mesmo tempo que se torna condição necessária para permanecer no jogo. A plena atividade está, portanto, inteiramente imbricada na perda de fronteiras entre o que é tempo de trabalho e o que não é (ABÍLIO, 2014, p. 200).

Ao final da leitura do livro de Ludmila Abílio fica claro que o trabalho destas revendedoras ofereceu um "percurso empírico" que possibilitou reconhecer esta plena atividade como expressão de um trabalho que ocorre de forma combinada em relação ao desemprego, ao trabalho formal e informal, ao trabalho doméstico, além de imbricar-se no consumo. Outra coisa que salta à leitura é a relevância da discussão sobre o setor de serviços atrelado à indústria de cosméticos e à informalidade revelada nas relações de trabalho relatadas, bem como na aparente subsunção da exploração e do próprio trabalho.

O que se revela de fato é a centralidade do trabalho recolocada sobre outros patamares de análise, buscando apreender a nova face destas reconfigurações em prol de maior acumulação, para além das aparentes: descentralização do controle e autonomia do trabalhador. Fica claro, a partir disso, que a centralidade do trabalho permanece fundante das dinâmicas sociais de produção e reprodução. O que ocorre é o aparente descentramento do trabalho potencializado por maneiras amórficas de organização da produção, acumulação e exploração no contexto atual. Portanto, a partir do texto da autora é possível entendermos que as novas configurações visualizadas não nos remetem somente às formas conhecidas das relações 
capital-trabalho-exploração do período industrial, com dimensões bem definidas, mas o que observamos, em setores como o de serviços e o informal, é uma latente complexificação das formas que potencializam ainda mais o capital, a lógica de acumulação e a exploração.

\section{REFERÊNCIAS}

CABANES, Robert; GEORGES Isabel. Perspectivas. In: CABANES, Robert et al. Saídas de emergência. São Paulo: Boitempo, 2011.

SANTOS, Silvio Matheus Alves. O trabalho flexível no comércio varejista: multifuncionalidade e precarização. Dissertação (Mestrado em Ciências Humanas), UFSCAR, São Carlos, 2013. Link: https://repositorio.ufscar.br/bitstream/handle/ ufscar/6751/5205.pdf? sequence=1\&isAllowed $=y$ 